\title{
CARDIAC CONCENTRIC HYPERTROPHY IN CHILDREN WITH HYDROCEPHALUS DUE TO TUBERCULOUS MENINGITIS
}

\author{
BY \\ JOHN L. EMERY \\ From the Department of Pathology, Sheffield Children's Hospital \\ (Received for Publication August 25, 1950)
}

During a necropsy on a child with internal hydrocephalus due to tuberculous meningitis, concentric hypertrophy of the left ventricle of the heart was noticed. Since that observation further cadavera were examined in greater detail for evidence of hypertension. In six out of a consecutive series of 16 deaths from tuberculous meningitis treated with streptomycin at the Sheffield Children's Hospital evidence was found suggesting hypertension.

\section{Case Summaries}

Case 1. The child's illness began with a cough at the age of 17 months, and he developed signs of tuberculous meningitis five months later. He had been undergoing streptomycin treatment for 18 months before death at the age of 3 years and 1 month.

At necropsy, the body was seen to be emaciated. There was opisthotonos, and the limbs were in an extreme spastic posture. There was marked internal hydrocephalus with much exudate at the base of the brain and over the cisterna magna. There was dilatation of the fourth ventricle with thinning

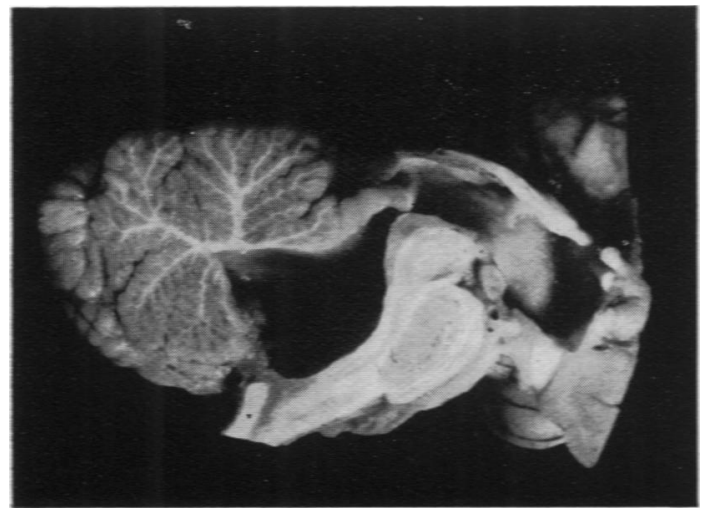

Fig. 1.-The fourth ventricle and pons from Case 1, showing thinning of the floor of the fourth ventricle, and exudate on the lower anterior surface of the pons and medulla $(\times 1)$.

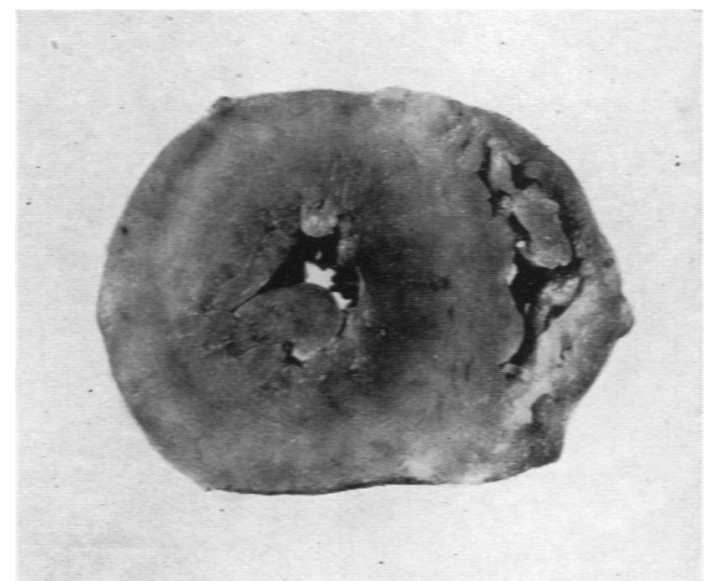

FIG. 2.-Transverse section of the ventricles of the heart of Case $1(\times 1)$.

of the pons and medulla (Fig. 1). All the viscera appeared to be wasted with the exception of the left ventricle of the heart. The liver weighed $384 \mathrm{~g}$. compared with the normal weight for that age of $420 \mathrm{~g}$. (Coppoletta and Wolbach, 1933); the kidneys (together), $75 \mathrm{~g}$. (normal $97 \mathrm{~g}$.); heart, $59 \mathrm{~g}$. (normal $59 \mathrm{~g}$.). The left ventricle appeared to be concentrically hypertrophied, the muscle being $14 \mathrm{~mm}$. thick (Fig. 2). No valvular abnormalities were found.

Case 2. Tuberculous meningitis began a month before treatment started. The child died, aged 2 years 8 months, after four months' streptomycin treatment. Teeth grinding and twitching began a month before death.

At necropsy the body was seen to be wasted and in a spastic posture. There was extreme flattening of the cerebral cortex with marked internal hydrocephalus, the cortex being $1-1.5 \mathrm{~cm}$. thick. The circulation of the cerebrospinal fluid appeared to be obstructed at the level of the tentorium. All the viscera appeared wasted. The liver weighed $328 \mathrm{~g}$. (normal $\mathbf{4 0 0} \mathrm{g}$.); the kidneys, 87 g. (normal 95 g.). The heart showed concentric 

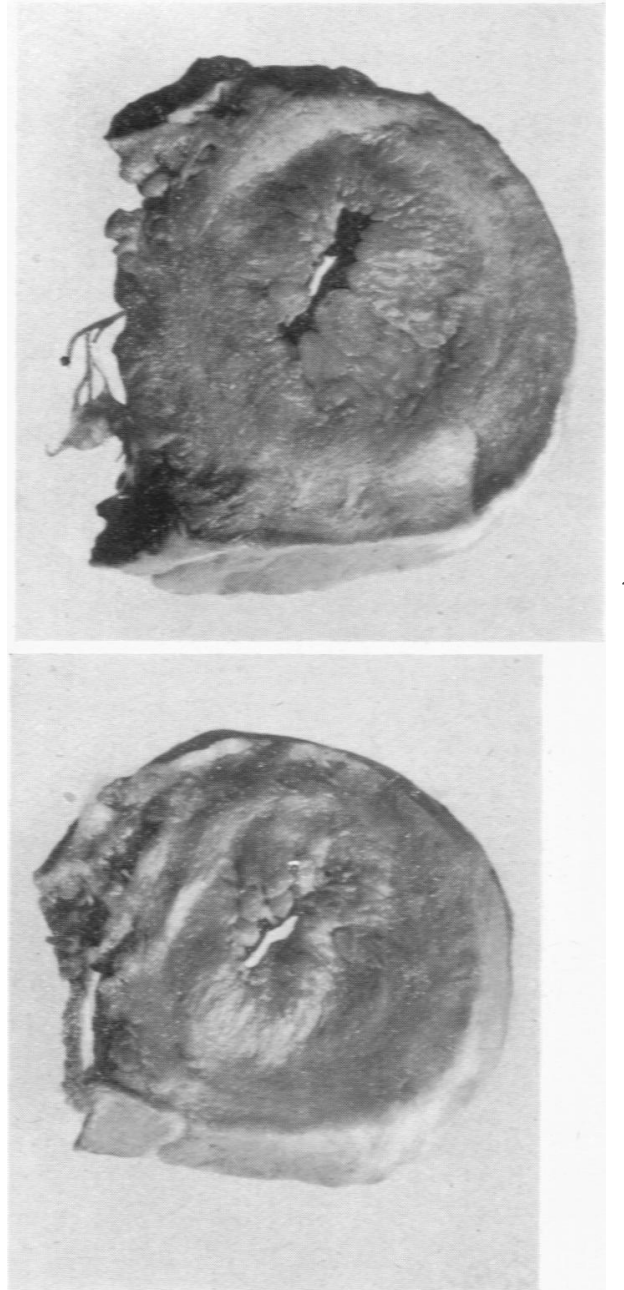

FIG. 3.-Transverse section of the left ventricle of Case $2(\cdot 1)$.

thickening of the left ventricle (Fig. 3), the muscle being $12-18 \mathrm{~mm}$. thick. No abnormality was seen in the valves or great vessels. The heart weighed $51 \mathrm{~g}$. (normal 58 g.).

Case 3. A boy aged $3 \frac{1}{2}$ years at death had been treated with streptomycin for $2 \frac{1}{2}$ months for tuberculous meningitis.

At necropsy there was marked hydrocephalus with thick fibrinous exudate about the base of the brain appearing to obliterate the cisterna magna. Many small areas of encephalomalacia were present. The heart weighed $64 \mathrm{~g}$. (normal $61 \mathrm{~g}$.), and showed some thickening of the left ventricle. Histology showed vessels in the liver and kidney with fibrinous degeneration of the muscle (Figs. 4 and 5).

Case 4. A boy, aged 9 years, fell ill with tuberculous

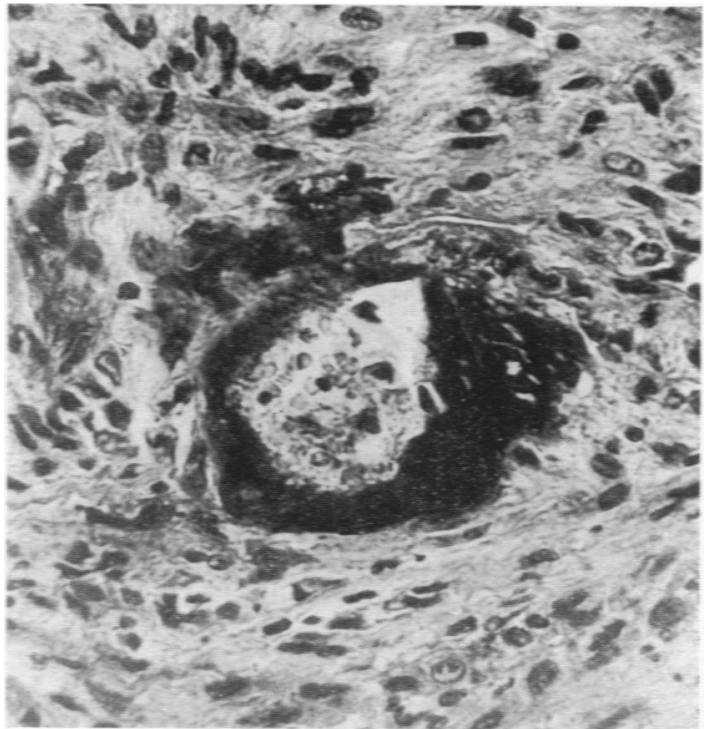

FIG. 4.- Section from the perirenal connective tissue in Case 3, showing hyalinization in a small artery. Sections stained with Masson's trichome, and photographed through a green filter $(\therefore 390)$.

meningitis four months before death. In the later stages contractions developed and a state of catatonic stupor.

At necropsy there was seen to be extreme wasting of the muscles and viscera. Moderate hydrocephalus was found, and generalized miliary tuberculosis. The heart weighed $140 \mathrm{~g}$. (normal $115 \mathrm{~g}$.): there was left ventricular hypertrophy, the muscle of the left ventricle being

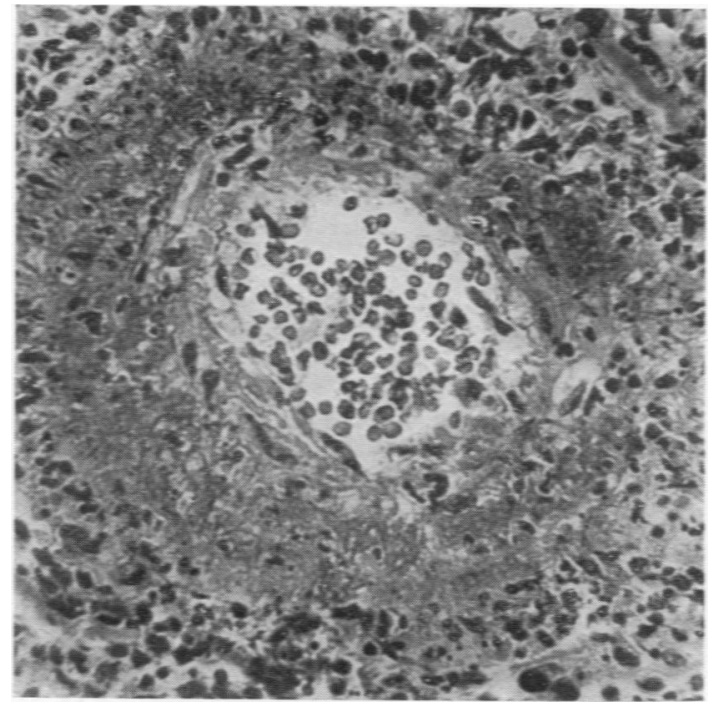

FIG. 5.-A small artery in the liver from Case 3 showing hyalinization and degeneration of the muscle (haemotoxylin and eosin $\times 390$ ). 
$13 \mathrm{~mm}$. thick. No abnormal lesions were found in the cardiac valves, the kidneys, or any blood vessels examined.

Case 5. A boy, aged $6 \frac{1}{2}$ years, died 14 weeks from the onset of meningitis.

At necropsy the body was seen to be extremely wasted. Old and recent miliary tuberculosis was present. The brain showed mild internal hydrocephalus with some dilatation of the fourth ventricle. The heart weighed $110 \mathrm{~g}$. (normal $97 \mathrm{~g}$.): the valves and vessels were normal. The left ventricle appeared to be concentrically thickened, the muscle measuring $13-14 \mathrm{~mm}$. The right ventricle measured 3-4 mm. No histological change was found in the visceral vessels, but the cerebral vessels showed the usual tuberculous endarteritis.

Case 6. A girl, aged 2 years 11 months, had symptoms of meningitis two months before treatment was started. After an apparent initially good response to streptomycin, her condition deteriorated and she died four months from the onset of the disease after severe convulsions which were only controlled by very heavy sedation.

At necropsy extensive hydrocephalus was seen, the thickness of the brain being $1-2.5 \mathrm{~cm}$. There was thinning of the base of the fourth ventricle. There was no visible generalized tuberculosis. The heart (Fig. 6) weighed $122 \mathrm{~g}$. (normal $61 \mathrm{~g}$.). The left ventricle showed considerable hypertrophy, measuring 13-17 mm. thick. No abnormalities were found in the valves or great vessels. The liver weighed $467 \mathrm{~g}$. (normal $426 \mathrm{~g}$.).

\section{Comment on Cases}

All the bodies were extremely wasted when they came to necropsy, and the weights of the hearts are not easy to interpret. The heart weights in several cases were higher than the average normal, but in all cases they were disproportionately high when compared with the diminished weight of the other

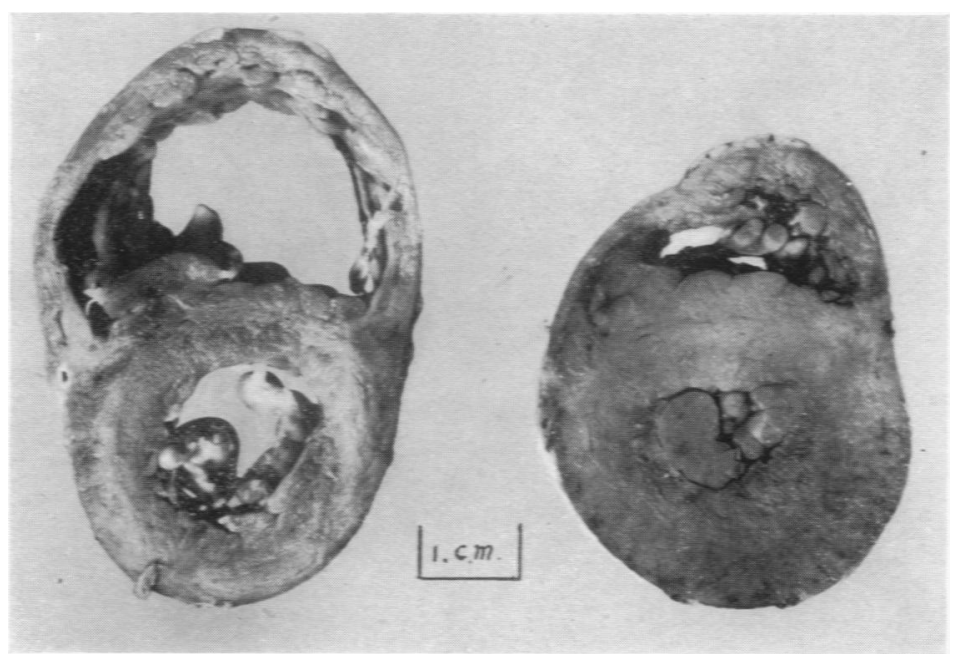

FIG. 6.-Transverse section of the ventricle of the heart in Case 6; also a section of a normal child's heart for comparison. organs. The change in the relative thickness of the left ventricle is best seen when compared with a normal heart of the same age (Fig. 6).

No anatomical abnormalities were found in the hearts or great vessels, and the heart muscle and coronary vessels were normal on microscopy. The changes in the left ventricles suggest a work hypertrophy. The most likely cause for the muscular hypertrophy is in association with a rise in systemic blood pressure, probably due to an increase in peripheral vascular tone.

\section{Discussion}

Since the observation by Naunyn and Schreiber (1881) that hypertension could be produced in animals by the injection of fluid under pressure into the cisterna magna, and by Cushing (1902 and 1903) that hypertension could be produced by raising the intracranial pressure, there have been a large number of studies of central nervous hypertension.

Cushing showed that the hypertension was obviated by the injection of cocaine, and Forster (1943) found that the site of the reaction was situated in the medulla, and that decerebration tended to enhance the hypertensive response to increased intracranial pressure.

The hypertension response was shown by Grimson, Wilson, and Phemister (1937) to require the presence of an intact sympathetic nervous pathway. Thomas (1941) showed that in dogs the response took place in the absence of the kidney, and Grimson (1940), after renal denervation. Griffith and Roberts (1938) showed that the hypertension was also independent of the adrenals or adrenalin.

Cushing had noticed that the major symptoms of the cerebral compression occurred with "an approaching capillary anaemia of the medulla,' and Nowak and Walker (1939) found that progressive ligation of various cerebral arteries resulted in chronic hypertension. Raab (1931) has shown that the hypertension may be produced by perfusing the vasomotor centres with lactic acid but not with alkali.

The method frequently used to produce persistent hypertension in animals has been to promote a chronic meningeal reaction by the injection of kaolin into the basal cisterns (Hamperl and Heller, 1934; Griffith, Jeffers, and Lindauer, 1935). Hamperl and Heller in 
histological studies of their hypertensive animals found foreign body reaction and granulation tissue around the medulla, blocking the foramina of Magendie and Luschka, and producing hydrocephalus. There was also perivascular 'round celled' infiltration. No abnormal vascular changes were found in the rest of the body.

I have been unable to find published records of hypertension produced by bacterial meningitis, but the association of hypertension with cerebral tumours involving the posterior fossa with bulbar types of poliomyelitis and pontine lesions are recognized. Meyer (1941) reported hypertension in four of five cases of tumour of the posterior fossa, and Ask-Upmark (1935) in an extensive review of cerebral lesions records an incidence of hypertension in $9 \%$ of cases of posterior fossa tumour, compared with $1.3 \%$ in those of anterior fossa tumour. The hypertension appeared to be independent of the cytology or particular area involved by the tumour. Three cases have been reported by Salus (1932), and one by Nordmann and Müller (1932) in which hypertension occurred associated with bulbar poliomyelitis. Serial section of the medulla showed extensive degeneration in the substantia reticularis grisea in which the blood pressure regulating centre is postulated.

Children with tuberculous meningitis now live longer than previously but frequently develop extensive internal hydrocephalus and inflammatory changes in the blood vessels of the brain. The cerebral lesions in these children are known to be chiefly due to vascular damage and ischaemia. This, combined with the rise in the intracranial pressure due to blockage of the cerebrospinal fluid, seems to produce the conditions which in experimental animals cause hypertension, and it is reasonable to expect minor degrees of hypertension to occur fairly frequently in these children.

In the rats in which hypertension was produced by kaolin Griffiths and Roberts (1938) noted that recovery from hypertension tended to occur in one to three months from the time of injection, and this suggests that the hypertension in children similarly would not be permanent.

It has not until now been part of the routine care of tuberculous meningitis in this hospital to take careful and regular blood pressure recordings, and for this reason no clinical evidence concerning blood pressure has been reported here. The necropsy findings in these cases do not, however, necessarily indicate that the blood pressure was raised to high levels, for, as Goldring and Chasis (1944) stress, the level of the blood pressure is not directly related to the severity of the vascular change, and it is possible that very small rises in the diastolic blood pressure may have produced the left ventricular hypertrophy. It is possible, however, that careful recordings of the blood pressure in tuberculous meningitis may serve as a guide to the presence of incipient medullary ischaemia.

\section{Summary}

The morbid anatomical finding of concentric hypertrophy of the left ventricle in six of a series of 16 children dying from tuberculous meningitis treated with streptomycin are reported.

It is suggested that the hypertrophy is due to hypertension of cerebral origin and is similar to the hypertension produced in animals by medullary ischaemia and by the cisternal injection of kaolin.

It is a pleasure to acknowledge the interest and helpful criticism of Dr. E. H. Harding. The photographs were taken by Mr. A. F. Taylor.

\begin{tabular}{ll}
\multicolumn{3}{c}{ References } \\
Ask-Upmark, E. & (1935). Acta psychiat., Kbh., \\
Suppl. 6. & \\
Cushing, H. (1902). Amer. J. med. Sci., 124, 375.
\end{tabular} - (1903). Ibid., 125, 1017.

Forster, F. M. (1943). Amer. J. Physiol., 139, 347.

Goldring, W., and Chasis, H. (1944). 'Hypertension and Hypertensive Disease.' New York.

Coppoletta, J. M., and Wolbach, S. B. (1933). Amer. J. Path., 9, 55.

Griffith, J. Q., Jeffers, W. A., and Lindauer, M. A. (1935). Amer. J. Physiol., 113, 285.

- and Roberts, E. (1938). Ibid., 124, 86.

Grimson, K. S. (1940). Proc. Soc. exp. Biol., N.Y., 44, 219.

_- Wilson, H., and Phemister, D. B. (1937). Ann. Surg., 106, 801.

Hamperl, H., and Heller, H. (1934). Arch. exp. Path. Pharmak., 174, 517.

Meyer, B. C. (1941). Arch. Neurol. Psychiat., 45, 468.

Naunyn, B., and Schreiber, J. (1881). Arch. exp. Path. Pharmak., 14, 1.

Nordmann, M., and Müller, O. (1932). Klin. Wschr., 11, 1371.

Nowak, S. J. G., and Walker, I. J. (1939). New Engl. J. Med., 220, 269.

Raab, W. (1931). Arch. intern. Med., 47, 727.

Salus, F. (1932). Klin. Wschr., 11, 1542 .

Thomas, C. B. (1941). Proc. Soc. exp. Biol., N.Y., 48, 24. 